\title{
Na fronteira: mobilidades xamânicas entre Brasil e Guiana Francesa
}

\section{At the border: shamanic mobilities between Brazil and French Guiana}

Ugo Maia Andrade*

*Universidade Federal de Sergipe - São Cristóvão, SE, Brasil ugomaiand@gmail.com 


\title{
Resumo
}

Um complexo cenário de relações caracteriza a fronteira entre o Brasil e a Guiana Francesa, guardada pelo rio Oiapoque e habitada por 7000 índios. Habituados a deslocamentos contínuos para os principais centros urbanos regionais, os povos indígenas do Oiapoque têm uma longa história de interação com aglomerados populacionais de brasileiros, créoles e Saramaká. Por conta disso, famílias karipuna, galibi-kali'na, galibi-marworno e palikur habitam a aldeia e a cidade, transitando regularmente entre ambas e proporcionando novos aportes de conhecimentos ao xamanismo regional que dinamizam, revitalizam e transformam práticas e ideologias xamânicas em diálogo com formas congêneres situadas do outro lado das fronteiras territoriais e/ou simbólicas. Este artigo busca explicitar etnograficamente esse campo de relações e discutir a presença das formas de mediação que emergem nas fronteiras (entre sujeitos, práticas rituais, territórios, etc.), propondo refletir acerca das transformações do xamanismo regional e das novas modalidades que ele vem assumindo.

Palavras-chave: xamanismo; fronteiras; conhecimentos; intercâmbios.

\begin{abstract}
A complex backdrop of relations characterizes the border between Brazil and French Guiana, kept by the Oiapoque River and inhabited by 7,000 Indians. Habituated to continuous displacements to the major regional urban centres, the Indigenous Peoples of Oiapoque have a long history of interaction with population clusters of Brazilians, creoles and Saramaká. Because of this, karipuna families, galibi-kali'na, galibi-marworno and palikur inhabit the village and the city, moving between them and providing new knowledges to the regional shamanism that revitalize and transform practices and shamanic ideologies in dialogue with similar forms from the other side of the territorial and/or symbolics borders. This article seeks to clarify ethnographically this field of relations and discuss the presence of mediation forms that emerge in the borders (between subjects, ritual practices, territories, etc.), proposing reflect about the transformations of regional shamanism and the new varieties that it have been taking.
\end{abstract}

Keywords: shamanism; borders; knowledges; exchanges. 


\section{Contexto}

O presente artigo ${ }^{1}$ pretende refletir acerca das transformações do xamanismo dos índios da região do baixo rio Oiapoque e rio Uaçá, fronteira Brasil-Guiana Francesa. Tais transformações são históricas e vêm sendo proporcionadas por trocas de conhecimentos, intensificadas em função do trânsito indígena entre cidades e aldeias localizadas em ambos os lados da divisa internacional. A área etnográfica em questão compreende o interflúvio Oiapoque-Cassiporé, no norte do estado brasileiro do Amapá, entre os paralelos $3^{\circ} \mathrm{N}$ e $4^{\circ} \mathrm{N}$. Além do curso inferior e estuário do rio Oiapoque está nela inclusa a bacia do rio Uaçá, formada pelos afluentes Curipi e Urukauá e por uma densa rede de igarapés que conecta lagos e lagoas em meio à floresta de terra firme e campos sujeitos à inundação de inverno.

A população indígena na região é constituída pelos Karipuna (rio Curipi), Galibi- Marworno (rio Uaçá), Palikur (rio Urukauá) e Galibi-Kali'na do curso inferior do rio Oiapoque. Tal contingente, formado por cerca de 7000 índios, distribui-se em mais de 40 aldeias em três Terras Indígenas (Uaçá, Galibi e Juminã) totalizando 518.454 ha. São povos multilíngues que, há mais de cem anos, adotaram o patois da Guiana Francesa como língua geral, conservando, não obstante, as línguas parikwaki (arawak) e o galibi (karib) nas comunicações intracomunitárias. É comum também o uso das línguas portuguesa e francesa, notadamente em contextos interétnicos, como assembleias e viagens.

Há muita variedade de peixes em toda a região do baixo Oiapoque, incluindo espécies provenientes do mar, como pescadas branca e amarela, que sobem os rios e igarapés para se alimentar. O verão é temporada de pescar fartamente piranhas e tucunarés que estão concentrados na calha dos rios ou nas lagoas e período do desejado pirarucu. Também é estação boa para a caça de aves que vão atrás da oferta suplementar de alimento, em especial aves de grande porte

1 Texto baseado em comunicação originalmente apresentada no simpósio Shamanisms in Movement, 54th International Congress of Americanists, Viena, 2012, retomando e refletindo aspectos apresentados em minha tese de doutorado (Andrade, 2007). Agradeço a Esther Jean Langdon, Anne-Marie Losonczy, coordenadoras do simpósio, e Florent Kholer pelos valorosos comentários feitos na ocasião do 54th ICA. Agradeço igualmente à Fundação de Apoio à Pesquisa e à Inovação Tecnológica do Estado de Sergipe (Fapitec) o apoio financeiro que facultou minha participação no congresso. 
que se concentram no leito dos rios: cigana, gavião marrom, mutum, garça e maguari. Na estação reversa, em que o nível da água sobe e os campos ficam inundados, a pesca é mais difícil porque os peixes estão espalhados, mas é a ocasião da pesca de aruanã e acará nos campos.

A oferta de caça varia conforme o período do ano e ambiente ecológico, mas em geral ela é relativamente abundante em toda a área. Acham-se macacos de tipos diversos, guariba, caititu, anta, paca, tatu, cutia, veado, jaboti e queixada na floresta e patos e pombas silvestres nos campos secos. Entre setembro e outubro, período de desova do camaleão, pega-se a fêmea desse animal atocaiada em buracos no solo arenoso às margens dos rios. Além da carne, preparada cozida, aprecia-se também os ovos, de sabor forte e casca maleável. Os animais que vivem na mata são mais abundantes no período de fartura de frutos e sementes silvestres dos quais se alimentam, tais como açaí, cunanã, murumuru, piquiá, anauerá, inajá e tucumã. É a época de engorda de tucanos, cutias, pacas e macacos, quando eles são achados facilmente próximos às zonas de concentração de seus frutos prediletos.

\section{Aldeia, cidade, aldeia}

Fundada em 1945 para auxiliar na colonização regional, Oiapoque é, basicamente, uma cidade de forasteiros que procuram melhores condições em uma fronteira onde circula euro e ouro. São pessoas oriundas especialmente do Ceará, Pará e Maranhão que chegaram no auge do eldorado e convivem hoje com a expectativa de uma alternativa econômica à produção aurífera, praticamente extinta nos garimpos da margem brasileira e cambaleante no outro lado. A exploração mineral foi um dos fatores precípuos de interação dos índios com estrangeiros ao longo do século XIX e início do XX, quando aqueles eram empregados nos garimpos abertos em suas próprias terras (então não demarcadas) ou os abasteciam de farinha e peixe salgado (Arnaud, 1970, p. 98). Atrás do comércio com os garimpeiros vinham também regatões árabes, chineses, créoles (provenientes da Guiana Francesa) e brasileiros cujo contingente foi parcialmente integrado à população indígena regional (Arnaud, 1970, p. 98).

Dados oficiais recentes indicam que Oiapoque é a quarta cidade do Amapá, com população de 25,5 mil habitantes (Instituto Brasileiro de Geografia 
e Estatística, 2017). Os índios vão à cidade de Oiapoque por motivos diversos, em especial a fim de vender excedentes de farinha e frutas e comprar mantimentos e outros gêneros nos mercados locais; em busca de serviços de saúde na Casa do Índio, serviços bancários e educação suplementar. Raramente vão à procura de trabalhos temporários, excursionando a Saint Georges ou Cayenne com esta finalidade e para a qual contam com a ajuda de redes de parentes e conhecidos que lá já estão. Com um percentual significativo de eleitores do município, a população da área indígena elege com regularidade representantes na câmara da cidade desde os anos de 1980, além de já ter feito um prefeito e de fornecer o secretário municipal para assuntos indígenas. Os que habitam a aldeia Manga às margens do rio Curipi e a cerca de $20 \mathrm{~km}$ da cidade - ou as aldeias da BR-156 são os que frequentam Oiapoque mais assiduamente, uma vez que, a depender da localização da aldeia ribeirinha, da embarcação, das condições de navegabilidade dos rios e da maré, a viagem para a cidade pode demorar até um dia.

Saint Georges fica a dez minutos de catraia da cidade de Oiapoque, à jusante, e é destino de brasileiros que vão procurar emprego e passagem para os que vão trabalhar clandestinamente em garimpo no outro lado do rio. Cidade ribeirinha com uma expressiva população palikur e local de trânsito para os Waiãpi do rio Camopi (alto Oiapoque), é preferida pelos índios do lado brasileiro para o comércio dos excedentes e de canoas, ambos pagos em euro. No entanto, desde 2005 a fiscalização francesa fechou o cerco ao comércio na cidade de qualquer produto vindo do Brasil, que oficialmente só pode ser feito mediante pagamento de altas taxas aduaneiras, inviabilizando as transações agrícolas indígenas. Cidade bem menor que Oiapoque, com comércio algo acanhado, Saint Georges tem uma população tão diversificada quanto a babilônia de origens que constitui a sua vizinha brasileira. Além dos Palikur - emigrados do rio Urukauá em diferentes períodos do século passado e que formam um bairro à parte dividido em duas comunidades, o Village Esperance 1 e Village Esperance 2 , diferentemente posicionadas em relação às tradições do grupo (Passes, 2006, p, 80) - a cidade abriga contingentes de Saramaká, chineses, créoles, haitianos, martinicanos, franco-europeus e brasileiros precariamente posicionados no mercado local de trabalho (Capiberibe, 2001, p. 113). Uma população flutuante de índios galibi-marworno e karipuna, casados com créoles ou não, fixou-se abaixo do bairro palikur e se integrou ao contingente de brasileiros precariamente empregados, retornando depois de alguns meses às suas aldeias 
de origem no Brasil ou seguindo para Cayenne, onde quase sempre possuem parentes. Quando não atuam como cozinheiros, pedreiros ou auxiliares de serviço geral, esses índios são contratados pelos créoles para brocar, limpar ou colher roças e fazer farinha, serviços que igualmente prestam aos Waiãpi do alto Oiapoque.

Uma pequena parcela dos brasileiros residentes em Saint Georges possui negócio próprio e permissão de trabalho. Estão no ramo do comércio de aviamentos, enquanto os imigrantes chineses, parcela significativa da população da Guiana Francesa, são proprietários dos maiores mercados da cidade. Não obstante o mosaico étnico, as posições na sociedade local e a distribuição de poder dentro dela estão mais ou menos sedimentadas: os Saramaká e créoles, maioria na Guiana Francesa e em Saint Georges, detêm as funções administrativas municipais; os franceses metropolitanos ocupam os postos de médicos, policiais, professores e enfermeiros; os chineses, conforme citei, são comerciantes, juntamente com créoles e Saramaká (Capiberibe, 2001, p. 114).

Com a inauguração, em março de 2017, da ponte binacional Brasil-França criou-se a expectativa de um fluxo livre de pessoas e veículos em ambas as direções, mas os franceses, temerosos por uma invasão de brasileiros desempregados e semiqualificados, acharam brechas para aplicar medidas que dificultam o acesso à Guiana, como a cobrança de uma taxa de quase 200 euros a título de apólice de seguro obrigatório automotivo, norma vigente na União Europeia. Na aduana de Oiapoque não há taxas para o acesso de veículos vindos do lado inverso da ponte, entretanto há um impeditivo, mais eficiente ainda que taxas, à circulação de carros de placa francesa (e outra qualquer) pela região: os $50 \mathrm{~km}$ não pavimentados da BR-156, dentro de área indígena, transformados em oceano de lama durante o inverno amazônico. A ponte e a estrada representam as duas principais ameaças às aldeias palikur, galibi-marworno e karipuna dispersas ao longo dos $90 \mathrm{~km}$ da BR-156 que atravessam a TI Uaçá e, simultaneamente, as expectativas de aumento da presença de turistas franceses no estado. Os próprios índios que residem às margens da estrada usam-na com certa frequência em deslocamentos até Oiapoque e Macapá e seriam beneficiados pela pavimentação. Poderiam também tirar proveito da ponte, uma vez que se deslocam para Saint Georges ou Cayenne, onde muitos têm algum parente.

Mas ambas as obras são vistas pelos índios do Oiapoque com muita apreensão, notadamente a pavimentação da BR-156 no trecho que transpassa a área 
indígena e cujas medidas mitigatórias vêm sendo infindavelmente negociadas há mais de dez anos. A tensão representada pela projeção dos impactos ocasionados pela pavimentação da BR-156; o desgaste da longa e escorregadia negociação pelas medidas mitigatórias; o ataque da mídia e da opinião pública locais, que culpam os índios por obstarem o progresso da cidade de Oiapoque ao exigirem o cumprimento dos acordos de compensação; o desmantelamento do escritório regional da Fundação Nacional do Índio (Funai), que outrora, sob a administração indígena, foi bastante atuante e referencia na solução de conflitos; tudo isso somado aos problemas crescentes atinentes à pouca oportunidade para os jovens, ao adensamento populacional das aldeias maiores e às incertezas da política indigenista levou, entre 2007 e 2008, uma série de perturbações às aldeias mais populosas, atingindo em especial alguns jovens que manifestaram comportamentos atípicos lidos, por lideranças indígenas locais, no viés da possessão xamânica por espíritos auxiliares dos pajés. Retomarei esse assunto ao final.

As primeiras aldeias da BR-156 foram criadas logo após a abertura da estrada no início dos anos 1980 e funcionariam como postos de vigilância contra invasores que, com a BR, teriam acesso facilitado à área indígena (Gallois; Ricardo, 1983, p. 9). Hoje o que preocupa é o aumento descontrolado desse acesso favorecido pela pavimentação da estrada. A composição e distribuição espacial de uma aldeia na região do baixo Oiapoque variam significativamente conforme o seu tamanho, localização e o grupo ao qual pertence. As aldeias menores, ribeirinhas ou localizadas ao longo da BR-156, tendem a se formar a partir de um único núcleo familiar extenso constituído por um casal mais velho e seus filhos solteiros residindo em uma casa em torno da qual gravitam os filhos casados e os filhos destes. No que concerne aos modelos de residência e descendência, os Galibi-Marworno e Palikur tendem a combinar uxorilocalidade e patrilinearidade, mescla idealizada pelos Karipuna apenas nas aldeias menores.

Não obstante a necessidade de assegurar o controle sobre o território inibindo invasões de pescadores, garimpeiros e caçadores através da recém-implantada estrada, e ainda considerando a atração que a oferta de caça nas florestas de terra firme desta porção da área indígena e de terra boa para plantar exerceram sobre as famílias emigradas, os deslocamentos que conduziram essas pessoas a se fixarem ao longo da BR-156 ocorreram e vêm ocorrendo também em função de dinâmicas de cisões intracomunitárias motivadas 
por desentendimentos entre afins ou vizinhos, adensamento populacional, rivalidades políticas, rixas circunstanciais ou ainda acusações de feitiçaria, demonstrando o vigor das práticas e ideologia do xamanismo na região. $\mathrm{Na}$ sequência, procuro demonstrar a amplitude e profundidade histórica das relações regionais, interindígenas ou não, lastreadas no xamanismo.

\section{Das trocas xamânicas}

No que concerne às relações regionais mediadas pelo xamanismo, Nimuendajú (1926) observou que o turé ${ }^{2}$ palikur registrava fortes relações de permutas de conhecimentos rituais deste povo com índios waiãpi e emerillon (do alto Oiapoque); e com a população créole da Guiana francesa. Em relação aos Waiãpi, a cooperação é marcantemente expressa pela presença de espíritos de antigos pajés waiãpi tornados Yumawali (espíritos auxiliares das montanhas) de pajés palikur: "Na noite de 4 para 5 de abril de 1925 assisti a uma dança de turé oferecida pelo pajé Maximilien ao seu aliado, o espírito de um finado pajé dos Wayapí" (Nimuendajú, 1926, p. 50).

Espíritos auxiliares provenientes dos créoles (termo genérico para a população mestiça da Guiana Francesa) também eram frequentes na cooperação com pajés palikur, motivo pelo qual os gadôs são, até hoje, reputadíssimos tanto como feiticeiros quanto como curadores (Nimuendajú, 1926, p. 49). Gadổé o nome que na Guiana Francesa se dá a oficiantes que fazem divinações, curas terapêuticas e produzem agressões por meio de espíritos auxiliares ou não. Seriam uma espécie de pajé mestiço ou urbano e dessa maneira são vistos pelos Karipuna e Galibi-Marworno. Os gadôs são considerados muito bons pajés. Possuem trânsito fácil entre Este Mundo e o Outro Mundo e visitam com regularidade seus Karuãna ${ }^{4}$ aliados, obtendo deles conhecimentos e fórmulas terapêuticas.

2 Turé é nome dado a ritos regionais onde são utilizados clarinetes homônimas. Variáveis na forma, esses ritos assemelham-se apenas pelo fato de utilizarem o mesmo instrumento sonoro principal.

3 Antonella Tassinari (1998, p. 255) diz que gadô pode ter relação com a palavra francesa regarder, traduzindo-se gadô por "aquele que pode enxergar".

4 Pessoas invisíveis do Outro Mundo, portadoras de invólucros vegetais ou animais e genericamente chamadas de Bichos. Atuam como espíritos auxiliares dos pajés. 
Relações mediadas por prestação de serviços xamânicos entre Palikur e Galibi do Uaçá (hoje Galibi-Marworno) são também mencionadas pelo etnólogo que testemunhou uma família inteira do Uaçá morando por dois meses na casa de um pajé enquanto a filha submetia-se a tratamento (Nimuendajú, 1926, p. 48).

As relações intercomunitárias entre os Palikur estiveram, no passado, completamente assentadas no xamanismo e as acusações de agressão dessa natureza já constam na história regional de mais de dois séculos atrás. Contudo, Nimuendajú, contrariando todas as narrativas sobre as relações entre os clãs palikur 30 anos após sua visita ao Urukauá, descreve a vida comunitária desse povo transcorrendo sob uma "uma atmosfera de harmonia e paz digna de nota" tão sólida que "nem mesmo a desconfiança das más ações do pajé Lexan Chevalier é capaz de perturbar; para rompê-la seria preciso que estranhos se intrometessem no seu meio" (Nimuendajú, 1926, p. 40). Para Nimuendajú, portanto, as clivagens provocadas pelo xamanismo na região do baixo Oiapoque eram devidas às relações interétnicas e raramente tinham peso em relações entre comunidades de um mesmo coletivo indígena.

O trabalho de Expedito Arnaud (1970) entre os Palikur e os Galibi do Uaçá reafirmará a tensão nas relações interfamiliares por conta de frequentes acusações de feitiçaria, comuns ainda hoje no rio Uaçá. Não obstante, o xamanismo enquanto ideologia era preservado, recaindo sobre os pajés a cólera das acusações de provocarem discórdias no meio coletivo por intermédio da prática da feitiçaria (Arnaud, 1996, p. 316-317). Por outro lado esse era o tempo dos grandes pajés cujos poderes, incomparáveis aos dos atuais, são hoje lembrados com discreta melancolia.

Segundo Expedito Arnaud, as relações de trocas de acusação de feitiçaria e de serviços terapêuticos no baixo rio Oiapoque incluíam a vizinhança não indígena, tanto da Guiana Francesa quanto do rio Cassiporé (Brasil). $\mathrm{Na}$ Guiana Francesa eram notadamente os pajés saramaká - procurados por índios brasileiros devido à sua reputação de competência para terapêutica e feitiçaria - que produziam acusações contra os pajés, especialmente aqueles da mesma ou da comunidade vizinha do consulente (Arnaud, 1970, p. 15). Os negros saramaká fazem parte das redes de relações dos índios da região do rio Uaçá desde a época em que chegaram ao rio Oiapoque, no século XVIII, após deslocarem-se da antiga Guiana holandesa (Price, 1983). Do Oiapoque foram para a bacia do Rio Uaçá explorar ouro e trocar pau-rosa, farinha e peixe 
com os índios, alargando, posteriormente, as relações para as trocas matrimoniais e xamânicas.

As relações dos índios da região do Uaçá com a população "brasileira" do rio Cassiporé, limite leste da TI Uaçá, tem sido historicamente mediadas por trocas comerciais, matrimoniais e xamânicas. No que concerne a estas últimas, Expedito Arnaud notou, nos anos de 1960, a prestação de serviços de pajés galibi do rio Uaçá às vilas ao longo do rio Cassiporé, expediente vantajoso para os pajés indígenas que recebiam de seus clientes brasileiros pagamentos em dinheiro e em bens materiais. Não obstante essa contratação de serviços dos pajés do rio Uaçá, os "pajés brasileiros" ${ }^{\text {"s }}$ do rio Cassiporé gozam ainda hoje de grande reputação dentre os próprios pajés indígenas da região do Oiapoque-Uaçá, posto que creditam a eles o consórcio com Karuãna brasileiros e indígenas, combinação que reúne conhecimentos diferentes e cuja síntese potencializa os poderes provenientes de cada tipo (Andrade, 2007, p. 106).

Todavia, inversamente aos pajés saramaká das vilas francesas de Saint Georges e Tampac (baixo Oiapoque), os pajés brasileiros do Cassiporé são, na avaliação dos pajés galibi-marworno e karipuna, apenas feiticeiros medianos. Comumente os relatos de relações com pajés brasileiros (às vezes também chamados de "portugueses") acentuam a cooperação e agressão controlada, ${ }^{6}$ sendo tais relações importantes em contextos de iniciação de reconhecidos pajés karipuna e galibi-marworno.

Esses segmentos xamânicos múltiplos na sua origem (indígena, saramaká, créole, brasileira) compõem um campo regional de disputas paralelas àquelas constitutivas da ação xamânica (por poder, força, prestígio) e dirigidas à prestação de serviços especializados (Andrade, 2007, p. 106). Segundo um hábito existente até hoje, índios karipuna e galibi-marworno residentes em Cayenne ou em Saint Georges, ou ainda em visita à Macapá, consultam-se com pajés

5 Esse é um termo relativamente recorrente em falas palikur, karipuna e galibi-marworno e não apenas os pajés o utilizam. Creio ser correto afirmar que "pajé brasileiro" agrega o pajé-sacaca e o raizeiro da classificação de Chaumeil (2015, p. 154), sendo, basicamente, um oficiante da pajelança urbana. $O$ traço distintivo local mais eloquente é que tais pajés têm como espíritos auxiliares Karuãna da cidade, espíritos de Saramaká e ainda entes congêneres da umbanda e candomblé.

6 Trata-se das medições mútuas de força entre dois pajés que, confrontando seus exércitos de Karuãna, simulam os embates verídicos que enfrentam. 
e outros oficiantes similares desses locais por acreditarem em seu conhecimento e competência ritual superiores. Mas o inverso é também verdadeiro e habitantes da Guiana Francesa vêm consultar os pajés indígenas por acreditarem que estariam eles mais próximos das fontes de poderes xamânicos provenientes da floresta e dos rios. Sobre tais relações que, reciprocamente, reconhecem a competência xamanística de pajés indígenas e não indígenas, testemunhou Expedito Arnaud (1970, p. 19):

[...] os xamãs e os feiticeiros do Uaçá, vêm sofrendo a concorrência de assemelhados seus crioulos e saramacás da Guiana Francesa e brasileiros do baixo Oiapoque e Cassiporé, os quais de quando em vez são consultados pelos índios. Porém, alguns deles têm estendido também as atividades até o âmbito dessas populações regionais.

O equilíbrio no campo regional de serviços xamânicos pode ser atribuído à repetição, por parte dos consulentes, daquilo que os próprios oficiantes consultados manifestam de certo modo: a convicção de que o poder xamânico aumenta conforme a distância e as fontes de conhecimentos às quais se tem acesso. Portanto, quanto mais longe estiver o pajé, mais poderoso ele tenderá a ser. Isso valerá também para os sopradores, uma modalidade de produtor de feitiços e curas por meio da recitação de fórmulas encantatórias (potás), cujos poderes aumentam conforme a distância geográfica e social em que se encontram em relação às suas vítimas em potencial.

Não obstante esses conhecimentos estarem distribuídos entre praticantes do xamanismo - e incluo aqui os adeptos dos potás - há técnicas de revide utilizadas contra pajés e que são perfeitamente acessíveis a não iniciados e aprovadas como eficientes. Dadas algumas especificidades de sua execução, essas técnicas são (ou eram) empregadas apenas para réplicas contra pajés da mesma comunidade da vítima, o tipo de conflito mais comum na área dentre aqueles originados das atividades do xamanismo. Mas não por acaso.

Uma tendência pretérita entre os Palikur na identificação de autoria de doenças provocadas por agressão xamânica consistia na imputação de responsáveis "de dentro", para vítimas individuais, e "de fora", caso se tratasse de uma epidemia (Fernandes, 1950, p. 311). Tal raciocínio pode ser explicado pela lógica da agressão que excluiria do assalto, ao menos, o grupo de substância 
do agressor. Como em uma epidemia toda a comunidade está sujeita à doença, elimina-se a possibilidade de que o autor do feitiço seja alguém de dentro, não restando dúvidas de que a agressão foi obra de um pajé estrangeiro ou do Outro Mundo. No que concerne às técnicas de revanche, elas consistiam primariamente na manipulação de objetos privativos do pajé que será atacado, sejam peças de seu vestuário ou seus instrumentos rituais, tais como maracá, banquinhos zoomorfos e bastão (Arnaud, 1970, p. 1-12).

\section{Buscando fronteiras: trajetórias}

O xamanismo é no baixo Oiapoque um conjunto de teorias e práticas que possibilitam a administração de relações entre domínios cosmológicos diversos onde estão pessoas humanas e extra-humanas igualmente diversas. Trata-se de interferir na entropia cósmica a favor da sociedade e dos homens, manipulando, negociando, controlando ou agenciando as múltiplas intencionalidades com as quais o pajé mantém consórcio (Andrade, 2012). Tal conjunto precisa ser aprendido pelo iniciado, ainda que o pajé neófito não passe por uma transmissão formal de conhecimentos porque é filho de Bicho ou pajé de nascença, produto da união de uma pessoa invisível (Karuãna, Bicho ou Yumawali) com uma mulher humana cuja gravidez ocorreu durante o período de suas regras.

Esse processo de transmissão formal de conhecimentos xamânicos é normalmente composto por protocolos que devem ser observados: 1) a aprendizagem de cantos de comunicação com as pessoas invisíveis; 2) o recurso a banhos com cascas de árvores-pajé; 3) uso intenso do tabaco, normalmente envolto na finíssima casca da árvore tawari e; 4) abstinências relacionadas ao trato com as pessoas invisíveis dotadas de formas vegetais, tais como evitação de alimentos portadores de pitchiu, como peixes e jacaré. Apresento a seguir, de forma bastante sumária, dois percursos de iniciação ao xamanismo protagonizados por reconhecidos pajés contemporâneos galibi-marworno e karipuna. Ambos os percursos sublinham a influência de pajés não indígenas no xamanismo regional.

O primeiro percurso é do pajé galibi-marworno Levên, um dos poucos hoje em atividade dentre esta população. Levên foi iniciado no xamanismo por volta dos 60 anos de idade, substituindo seu irmão mais velho, Arsênio, 
que, assediado insistentemente pelos Karuãna de seu pai, o grande pajé Chinois, declinou do ofício. Arsênio não conseguiu reverter os efeitos da doença ocasionada pela presença dos Karuãna em seu corpo e morreu, deixando para Levên o poderoso maracá de Chinois e o conselho para ele tornar-se pajé. Para que isso acontecesse seria necessário passar os Karuãna de Arsênio para Levên, operação delicada e realizável apenas por um pajé habilidoso. Essa tarefa coube a Cecília, uma pajé galibi-marworno que residia na cidade de Oiapoque e era prima (FZD) de Levên, não obstante ele a chamasse de tia.

Outro protagonista no percurso de iniciação de Levên é um pajé, residente em Macapá e que ora é descrito como índio urubu-kaapor, ora é um gadô. Ambos atributos serão, contudo, consistentes se atentarmos para o fato de eles deslocarem esse protagonista para uma distância maior em relação ao próprio Levên, atribuindo-lhe uma superior capacidade xamânica, conforme se vê em narrativa do próprio Levên:

[...] Não vê esse gadô de Macapá, meu amigo, sobre quem eu falei? Ele trabalha com todos esses negócios. E vira Bicho mesmo. A mulher dele estava me falando, ele tinha saído, ela chegou pra conversar e disse: "Meu marido é Bicho, é gente, mas é Bicho. Não é toda semana, mas tem sexta-feira que ele sai, vai lá na beira d’água. O Bicho [Cobra Grande] boia e ele pula em cima. Depois some n'água, seis e meia para sete horas da noite." Eu mesmo cansei de levá-lo: "Vamos lá na beira que eu vou passear. A cidade é grande, lá a cidade é grande." Chegava perto d'água, pegava o charuto dele, botava fumaça; não demora e o Bicho boiava, grande. Ele subia e sumia no fundo. Uma vez ele falou: "Vamos comigo, vamos comigo pra você ver como é bom lá."

Você não quis ir?

Não, fiquei com medo. Sabe aonde ele vai? Ele vai para o centro do mar. É lá que tem gente bonita, tem mulher bonita, tem cidade grande. No fundo dágua.

É grande como Macapá?

É maior, como capital grande.

Tem tudo que tem na cidade?

Tudo, é do mesmo jeito. É diferente, porque é no Outro Mundo. Ele dizia: "Vamos, amigo, vamos comigo pra você conhecer como é e aprender coisas lá." Eu pensava: "Eu posso chegar bem, mal ou morto. Eu não vou não." Eu também estava na Casai [Casa de Saúde Indígena], não podia sair. Eu queria ficar 20 ou 30 dias 
trabalhando junto com ele pra me formar. "Se você passar 20 ou 30 dias, trabalhando comigo, você vai se formar mesmo."

Essa cidade aonde ele vai é só de amigos dele?

É sim. Ele me diz que o remédio que ele tem vai buscar lá. Quando falta remédio ele vai buscar lá, pula na água e vai embora. Volta trazendo, põe na garrafa e pronto.

Como pajé urbano e acostumado às diversas formas de procedimentos rituais de terapêutica e agressão, um gadô consegue produzir a "totalização dos pontos de vista singulares e irredutíveis" (Carneiro da Cunha, 1998, p. 17) de cada alteridade com a qual transaciona. Por isso é considerado um pajé poderoso e capaz de lidar com uma multiplicidade de situações e de encontros. São essas qualidades que justificam sua presença nos contextos de iniciação de pajés karipuna e galibi-marworno.

A segunda trajetória de introdução no xamanismo é a do poderoso pajé karipuna Aniká, falecido em 2009. Não possuo registro gravado, apenas as notas de campo. O riquíssimo curriculum vitae de Aniká pode ser assim resumido: ex-cabo do Exército Brasileiro, tendo inclusive estado na guerrilha do Araguaia nos anos 1970; chefe de posto e cacique do Encruzo, aldeia de monitoramento que existiu no encontro dos rios Curipi e Uaçá, por mais de 30 anos e um dos fundadores da aldeia Manga, a maior dos Karipuna. Precocemente, aos 12 anos de idade, ele fez sua primeira sessão de cantos e curas xamânicas na aldeia Espírito Santo, rio Curipi, casando-se no ano seguinte. Aos 18 anos de idade e morando no Marupi, no rio Oiapoque, com sua família, sua mãe o levou até a vila Tampac, no rio Camopi, alto Oiapoque, a fim de passar por ensinamentos xamânicos com o pajé saramaká Panô. Durante um mês experimentou um intenso treinamento, submetido a uma dieta alimentar que consistia tão só de uma xícara pequena de cachaça pela manhã, outra ao meio-dia e outra à noite, acompanhadas por cigarros de tawari que ele fumava compulsivamente.

A escolha da mãe de Aniká por um pajé saramaká deu-se pelas boas relações que ela e o marido mantinham com os Saramaká vizinhos e porque seus pajés são reputados como perigosos e conhecedores de fortes tchembuá, feitiços poderosos que nenhum pajé indígena consegue reverter. Após a experiência em Tampac, Aniká esteve no rio Camopi onde permaneceu por mais um mês com os pajés waiãpi (ou emerillon?) Kaimã, Chandele (filho do primeiro) e Anapi. 
Segundo Aniká, ele foi "garantido" por esses três pajés, tendo seu corpo e espírito trabalhados, tornando-se imune às agressões xamânicas de outros pajés e gadôs. Ao contrário de sua estadia em Tampac, no Camopi não havia restrições alimentares tão severas e sua alimentação consistia de beiju e carnes de caça preparadas à maneira da cozinha waiãpi local: moqueada e insossa.

Durante os estágios xamânicos em Tampac e no Camopi, Aniká foi preparado para receber Karuãna waiãpi e saramaká e sempre contou com o auxílio de seus iniciadores para protegê-lo de Karuãna de pajés hostis durante os trabalhos rituais ou na vida cotidiana. Essa era a retribuição deles pelos serviços que Aniká lhes prestara traduzindo os Karuãna que falavam línguas conhecidas por ele e que chegavam durante os trabalhos rituais feitos por seus mestres. Quando resolveu se aposentar das atividades de pajé procurou por Panô, em Tampac, baixo Oiapoque, a fim de comunicar-lhe a decisão.

Aqui ficam claras as relações cooperativas com "pajés perigosos" mantidas por Aniká ao longo de toda sua carreira como pajé. Talvez a escolha por ter esses pajés como mestres tenha sido uma estratégia deliberada: antes ter pajés saramaká e waiãpi como aliados a tê-los como inimigos. E dentre as permutas estabelecidas estão conhecimentos específicos adquiridos ao longo das biografias: conhecimentos xamânicos, herdados por quem ocupava posição em uma linha de transmissão de direitos e deveres rituais (Panô e os pajés waiãpi), e linguísticos, somados por quem, na qualidade de militar do Exército Brasileiro, havia percorrido muitos lugares e conhecido hábitos e modos de vida diversos (Aniká).

\section{Final: que fronteiras?}

Não tenho a oferecer uma conclusão propriamente, mas farei a tentativa começando por sublinhar que as transformações do xamanismo na região do baixo rio Oiapoque e rio Uaçá - que ocorrem por razões internas e externas - são históricas, diligentes e criativas. Langdon (2012) mostrou como as diferentes respostas de xamãs siona e sibundoy às demandas por serviços terapêuticos de medicina popular e curandeirismo na Colômbia de meados do século XX refletiram diferenças nas experiências desses povos com a sociedade envolvente, de tal modo que suas respostas foram mais históricas que atinentes às variações 
regionais do xamanismo. E não obstante a entrada tardia na rede de curandeirismo constituída por xamãs indígenas e mestiços, o xamanismo siona logrou revitalização e grande projeção nacional, sob o auspício do rótulo do "índio ecológico" (Langdon, 2016, p. 25).

Tal projeção só foi possível por causa da articulação com xamãs mestiços que, por seu turno, compartilham com os xamãs indígenas os mesmos princípios etiológicos e procedimentos clínicos. O curandeirismo, portanto, emerge em um quadro de relações interétnicas lastreadas em saberes e práticas médicas comuns a oficiantes indígenas e mestiços, recordando a emergência de pessoas (os grandes pajés) e sistemas de cura/agressão no baixo Oiapoque e rio Uaçá, formados exatamente a partir do contato com não índios. Refiro-me, em especial, aos grandes pajés karipuna Aniká, Elza (mudada para a Guiana Francesa) e Manoel Jorge, tão conhecidos dentro da área indígena quanto fora e produtos eloquentes de intercâmbios interindígenas e com pajés brasileiros da região ou saramaká da Guiana Francesa. Poderíamos indagar pelos fatores que levaram essas pessoas a se tornarem pajés excepcionais, de prestígio transnacional, investigando a articulação entre índios e não índios, no que concerne às práticas médico-populares, a partir de um ponto de vista histórico (Langdon, 2012, p. 63) que compreenda tanto as biografias quanto a posição do xamanismo indígena nas redes de intercâmbios com práticas e saberes congêneres não indígenas.

A revitalização do xamanismo amazônico após os empreendimentos coloniais/neocoloniais que, direta ou indiretamente, o combateram (a atividade missionária, a exploração borracheira, as rotinas civilizatórias estatais, os descimentos, a escravização indígena, etc.) valeu-se e tem sido ainda beneficiada por redes locais e supralocais, interindígenas ou não (Langdon, 2016, p. 33), demonstrando o vigor do xamanismo em se articular com forças múltiplas, o que, de resto, é (a articulação com alteridades díspares) a sua principal habilidade.

O que se percebe é que modalidades regionais de xamanismo não indígena (por assim dizer) reconhecem o prestígio do xamanismo que vem das aldeias, incorporam signos que seriam a sua síntese, para então serem acessadas e (re) indianizadas por pajés que se deslocam até as cidades, como fazem com frequência os Karipuna e Galibi-Marworno ao incorporarem discursos e procedimentos rituais provenientes de matrizes como a umbanda ou formas análogas 
(Andrade, 2007), revelando "um duplo movimento de intercâmbio xamânico, da floresta à cidade e vice-versa" (Chaumeil, 2015, p. 153). Se, por um lado, os pajés indígenas são admirados por seus análogos não indígenas e sua clientela, ao se situarem em relação às práticas médico-populares amazônicas eles encontram terreno promissor para "expandirem seu papel em um sistema em que para um curandeiro a identidade indígena é um importante capital simbólico" (Langdon, 2012, p. 69). Essa é a principal razão da vasta clientela urbana de pajés como Aniká, Cecília (a tia-prima de Levên, residente em Oiapoque) e Manoel Jorge (muito procurado por pessoas da vila de Cassiporé). Considere-se também a já demonstrada avidez dos pajés da TI Uaçá por conhecimentos e técnicas de cura/agressão de pajés saramaká e brasileiros, mostrando que o desejo por conhecer e dominar o xamanismo alheio recobre todos os termos de uma relação onde poderes de cura/agressão são diretamente proporcionais ao grau de alteridade de seus detentores. Vejamos, nesse sentido, outra narrativa de Levên:

Quando eu cheguei na beira da rua [em Macapá], assim andando, estava procurando onde estavam esses gadôs. Haviam me dito que eles trabalhavam naquele pedaço. Uma mulher me viu e encostou: "O que está procurando?" Eu disse: "Estou olhando assim, procurando um gadô que faça remédio." “É, pode subir. É aqui mesmo. Quer fazer consulta?" "Eu queria ver se não está muito caro." “Não está caro não, são dez reais. Quer fazer, vamos logo." Fomos por uma escada, subimos lá em cima. Entramos, só eu e ela, começamos a conversar. Ela pegou em minha mão: "O senhor tem cigarro?" "Tenho uma carteira." "Me dê um cigarro." Começou a fumar, conversamos. Tinha uma santa bem preta, bem preta. Estava lá. Tinha um copo, uma chave, chave fechada, pendurada. Eram as coisas dela. Ela olhou assim pra mim: "Olhe, eu lhe digo logo: o senhor está assim, assim, assim. Está meio baqueado, mas, vamos ver; se eu tiver remédio pra você eu lhe digo na hora." "Está bom." Ela pegou o copo, derramou um pouco de água dentro, até o meio do copo, pegou a chave e jogou na água, "tchum". "Bota seu dedo aí, bota esses dois dedos aí." Eu botei. Ela levantou, veio por trás de minhas costas começou a rezar e com três minutos, a chave abriu, "vuuuu", dentro do copo. "Pode tirar a mão. O remédio é assim, assim, assim. São trezentos reais por tudo, completo." Aí fiquei...: “Eu não tenho dinheiro, já, já não. Amanhã ou depois é que vou ter." Ela disse uma palavra que nunca vi, que nunca conheci. Falou a verdade; parece que já conhecia há muito tempo: "Você tem sua esposa aqui." 
Eu falei: "Está lá na Casai, internada com isso assim, assim." "Eu não quero saber a doença dela. Vou lhe contar o que ela tem." Ela me contou tudinho, bem certo. Eu fiquei olhando: "Quem contou pra essa mulher que minha esposa está com isso, sofrendo daquilo? Quem contou?"

A narrativa repete o prestígio que os gadôs possuem na apreciação de Levên: produtores/detentores de extraordinárias fórmulas fitoterápicas e habilíssimos nas práticas divinatórias. É com esses oficiantes - que empregam de maneira criativa diversas matrizes rituais, extraindo sua força dessa mestiçagem simbólica - que os pajés karipuna e galibi-marworno às vezes se consultam quando vão à cidade, usando seus serviços de divinação ou de herbarista. Se os pajés mestiços, no sentido concedido acima, gozam de boas prerrogativas como tradutores - no sentido dado por Carneiro da Cunha (1998) - é notadamente porque eles próprios são frutos da unificação de pontos de vista culturais diferentes, conhecendo-os, supostamente, melhor e aproveitando melhor também as fontes de poderes oriundos desses lugares.

Peter Gow (1994, p. 95) indica que o xamanismo urbano na região do baixo Urubamba consiste no amansamento dos espíritos da floresta - os arcanas ou incantos, considerados pessoas - para que estes emprestem seus poderes de cura ao pajé que, por sua vez, estabelece a comunicação com eles por meio da ingestão da ayahuasca. ${ }^{7}$ Trata-se de um retorno aos primórdios da história (condensada no imaginário sobre a floresta) e somente o pajé mestiço pode fazê-lo, já que ele, do ponto de vista amazônico, é o único cuja origem repousa na história da região: "Mestizos, the 'mixed-blood people' descended from whites and Indians, living between the cities and the Forest, become the masters of the paths between them" (Gow, 1994, p. 104). Assim, o próprio surgimento na Amazônia de um xamanismo com ayahuasca deveu-se à formação do mestiço enquanto uma categoria social, somando-se o desenvolvimento dos centros urbanos da região e o ciclo da borracha (Gow, 1994, p. 105, 2001, p. 137).

Tal xamanismo é tributário de um modelo histórico de relações sociais (associadas, no caso do baixo Urubamba, à exploração borracheira) vigentes ainda hoje, produzindo respostas tanto para a experiência com a doença entre

7 Além da ayahuasca, utiliza ainda o tabaco e o toé (Datura insignis). 
os mestiços quanto para as circunstâncias históricas de suas aflições (Gow, 1994, p. 111). E qualquer que seja o rendimento clínico que o xamanismo mestiço possa proporcionar, no baixo Urubamba ou nas cidades da Amazônia brasileira, sua principal fonte de poderes estará ligada à floresta, ${ }^{8}$ completando um caminho do hoje às origens.

Sabe-se que modalidades de xamanismo ayahuasqueiro estão hoje muito além das aldeias, sendo um dos principais produtos de exportação da Amazônia indígena, alimentando um efervescente mercado global de bens xamânico-espirituais que inclui demandas por símbolos, artefatos e práticas terapêuticas. O xamanismo com uso de ayahuasca serve como ilustração da plasticidade, da capacidade de incorporação, adaptação e transformação do xamanismo indígena em geral que, mesmo antes de sua abertura recente ao Ocidente,

[...] aparece como un conjunto abierto de prácticas rituales, caracterizadas por su alto nivel de improvisación y por su papel mediador frente a la irrupción de innovaciones exteriores a la sociedad, activando dispositivos culturales que permiten su aclimatación y adaptación a las nuevas circunstancias. (Losonczy; Mesturini Cappo, 2010, p. 167).

Assim, o xamanismo é um saber ritual sempre em movimento e tanto as redes quanto os mercados (estes mesmos redes) contemporâneos de alternativas terapêuticas e bens espirituais de base xamânica podem ser vistos como transformações amplificadas de antigas redes interindígenas de trocas de conhecimentos que, com o encontro colonial, passaram a incluir novos atores, inaugurando contextos inéditos de interlocução onde "shamanisms today constantly emerge and recreate themselves in a dialogical relation between actors in a post-colonial and post-modern world" (Langdon, 2013, p. 31).

A ideia do xamanismo como "saber ritual sempre em movimento" (Losonczy; Mesturini Cappo, 2010, p. 167) é congruente com a caracterização etnográfica de xamãs amazônicos enquanto simulacros de dínamos culturais: quanto mais movimento (deslocamentos), mais energia (poder). Essa realização é verdadeira

8 Como seus consortes urbanos amazônicos, os pajés andinos atribuem à floresta grandes poderes xamânicos - devido aos agentes extra-humanos que lá habitam - temendo e admirando o potencial predatório dos pajés ameríndios da floresta (Chaumeil, 1992, p. 102). 
tanto para o plano do invisível quanto do visível, uma vez que são os deslocamentos para domínios extraempíricos, normalmente locais de morada de seus espíritos auxiliares, que produzem a força ritual de um pajé, ao passo que as viagens empíricas - sejam elas para intercâmbios ou reivindicações de natureza múltipla - garantem-lhe robustez política. Assim é que notórios pajés galibi-marworno ou karipuna de outrora são lembrados como tendo sido também grandes caciques, a exemplo de Chinois (pai de Levên), o já bem citado Aniká e o lendário Uruçu, personagens qualificáveis a partir de imagens-síntese que marcam a função precípua cosmopolítica de um xamã, a exemplo do curaca, do tuxaua, do messias e de todos os líderes indígenas político-religiosos que, usando o xamanismo como esquema cognitivo de explicação/interpretação de um mundo em devir onto-histórico, guiaram o destino de comunidades inteiras. ${ }^{9}$

O movimento, pois, é constitutivo do xamanismo, o que explica a sua excepcional capacidade de digerir eventos a fim de recolocar a ordem no mundo. Nos episódios marcantes das abruptas alterações comportamentais de jovens das aldeias populosas da TI Uaçá, entre 2007 e 2008, as lideranças indígenas, algo desesperadas, acionaram Funai, Secretaria Especial de Saúde Indígena (Sesai), os pajés locais e ainda mandaram buscar renomados pajés urbanos da região. Exceto os psiquiatras enviados pela saúde indígena, todos pareciam estar dispostos a concordar que a causa do problema era a possessão desses jovens, garotos e garotas, por Karuãna, espíritos auxiliares dos pajés, surgindo, daí, a necessidade de execução de xitotós a fim de se verificar a razão de tais ataques sobrenaturais e buscar os meios necessários à sua pacificação. Esse foi um período tenso para os índios do Oiapoque.

Dois grandes projetos governamentais, que afetariam diretamente a vida de comunidades inteiras, estavam sendo iniciados: a pavimentação do trecho dentro da TI Uaçá da BR-156 e a implantação de uma linha de transmissão de energia elétrica que, cortando a mesma TI, acabaria com a dependência da cidade de Oiapoque da energia elétrica gerada a partir da combustão de óleo diesel. Esses dois eventos exigiram dos índios uma mobilização coletiva

9 Vale também para Davi Kopenawa, hoje a mais emblemática liderança amazônica, intelectual de grande porte, passe livre no alto circuito político internacional, xamã e diplomata, "uma só e mesma posição" (Viveiros de Castro, 2015, p. 22). 
intensa e eficiente, mas ainda assim a tensão e incertezas continuaram. Se eles têm ou não alguma conexão com o comportamento atípico dos jovens, é outra história. $\mathrm{O}$ fato é que, no contexto em que tais alterações surgem, os projetos estavam sendo iniciados, ou quase isso. Mas foi a explicação dos ataques dos Karuãna que se tornou hegemônica até mesmo entre lideranças que mantinham alguma distância do universo local do xamanismo. Não cheguei a conhecer em detalhes o prognóstico (ou prognósticos) para os ataques dos Karuãna, nem as medidas que sucederiam, mas creio que estavam associadas, de alguma forma, ao encaminhamento da interlocução com os agentes (governo e empresas privadas executoras) responsáveis pela pavimentação da estrada e pelo linhão de energia elétrica.

Explicar eventos históricos a partir de uma moldura cosmológica que, simultaneamente, se abre para a história, revelando um mecanismo de "estrutura de conjunturas" (Sahlins, 2004) não é novidade antropológica alguma, mas é a capacidade do xamanismo de se manter coerente enquanto engenho de produção de respostas que chama a atenção. E não obstante as transformações, suas múltiplas configurações representam ainda

[...] formas originais que não são uma réplica de seu passado distante, nem a pálida cópia dos modelos impostos, e apresentam evidentemente algo bem diferente de um simples amontoado de elementos heteróclitos tomados das diversas tradições religiosas que invadiram seu território. (Chaumeil, 2015, p. 156).

Curiosamente, essas diversas "tradições religiosas invasoras" relatadas por Jean-Pierre Chaumeil (1992; 2015) parecem ter se incorporado integralmente a certas configurações do xamanismo amazônico, a exemplo do curandeirismo, da pajelança, do vegetalismo e de outras formas investigadas pelo próprio autor. Tais incorporações têm sido o solo fértil de permanência do xamanismo amazônico que, seguindo a célebre lógica de Historical metaphors and mythical realities, continua por meio das transformações, possibilitando-nos reconhecer uma identidade subjacente à diversidade das práticas e ritos xamânicos. Penso que a questão de até onde podemos chamar práticas diversas e, às vezes, heteróclitas de xamânicas deve ser abordada com recurso a uma teoria etnográfica da aculturação (Gow, 2015, p 36), capaz de confrontar nossas ideias acerca das fronteiras entre saberes e práticas voltados à interlocução e mediação cosmológicas 
e interespecíficas; ou acerca de nossas convicções sobre a produção de diferenças com recurso a conceitos que evocam unidades primordiais diferenciantes.

A aparente pulverização do xamanismo gerando novíssimas configurações, como o cyber xamanismo, e associações, a exemplo das comunidades virtuais e dos congressos on-line, ${ }^{10}$ conduz-nos, potencialmente, a nostalgias, mas, igualmente, impõe o desafio da criação de ferramentas conceituais e metodológicas a fim de seguir esses novos movimentos xamânicos em face dos quais os modelos convencionais das redes de trocas de conhecimentos talvez não garantam bom rendimento analítico. Isso porque "o fenômeno xamânico constitui hoje uma paisagem multissituada, desenhada pelos deslocamentos regulares à longa distância de especialistas rituais e praticantes bem como pela disseminação e reconfiguração constantes dos discursos e das práticas" (Losonczy; Mesturini Cappo, 2011, p. 10), promovendo novas formas de mobilidade e itinerância que estão além das clássicas explicações sociológicas dos processos migratórios (Losonczy; Mesturini Cappo, 2011, p. 10). Surge, assim, a necessidade de uma etnografia itinerante que possibilite a compreensão de deslocamentos intercontinentais de oficiantes/terapeutas e neófitos/pacientes consorciados a práticas xamânicas de cura, em especial ayahuasqueiras; e que permita também indagar a respeito "das continuidades e rupturas que conectam às formas mais vernaculares ou mais localizadas" de xamanismo (Mesturini Cappo, 2013, p. 120).

Seria pertinente pensar, perfilado a Langdon (2012), que o xamanismo é um fenômeno de emergência constante e capaz de assumir configurações concretas, segundo a interação local de fatores culturais, históricos, demográficos e sociais (Langdon, 2012, p. 81-82) que, todavia, podem ser de origem supralocal. É essa natureza líquida do xamanismo que igualmente permite aos povos amazônicos realizarem o desejo de agregar às suas práticas xamânicas alteridades díspares, sob a forma de conhecimentos e procedimentos exógenos e, assim, potencialmente fontes de poder, e cujo uso deve passar pelo crivo dos processos sociais capazes de transformar o risco em fertilidade.

10 Um dos maiores deles é o XAMÃSCONET - Congresso Internacional de Xamanismo na Internet (http://conscienciaprospera.com.br/xamasconet-congresso-internacional-de-xamanismo-na-internet/). 
Diante das dinâmicas das incorporações do xamanismo indígena - que visam ascender a conhecimentos xamânicos novos e poderosos a fim de potencializar seu próprio xamanismo - cabe perguntar se caberia mesmo perguntar onde ficam as fronteiras. O que separa um e outro xamanismo? Pois, afinal, tais perguntas não marcariam o desejo discreto que às vezes manifestamos de preservar "formas autênticas" de xamanismo indígena, enxergando perdas e subtrações onde os próprios índios parecem ver ganhos e adição?

\section{Referências}

ANDRADE, U. M. O real que não é visto: xamanismo e relação no baixo Oiapoque. 2007. Tese (Doutorado em Antropologia Social)-Faculdade de Filosofia, Letras e Ciências Humanas, Universidade de São Paulo, São Paulo, 2007.

ANDRADE, U. M. Sobre artefatos-pessoa e produção ritual no baixo Oiapoque (Amapá). Revista de Antropologia, São Paulo, v. 55, n. 2, p. 971-1016, 2012.

ARNAUD, E. O xamanismo entre os índios da região do Uaçá. Boletim do Museu Paraense Emílio Goeldi, Belém, n. 44, p. 1-22, 1970. (Nova série, Antropologia).

ARNAUD, E. O sobrenatural e a influência cristã entre os índios do rio Uaçá (Oiapoque, Amapá): Palikur, Galibi e Karipuna. In: LANGDON, E. J. M. (Org.). Xamanismo no Brasil: novas perspectivas. Florianópolis: Editora da UFSC, 1996. p. 297-332.

CAPIBERIBE, A. M. G. Os Palikur e o cristianismo. 2001. Dissertação (Mestrado em Antropologia Social)-Instituto de Filosofia e Ciências Humanas, Universidade Estadual de Campinas, Campinas, 2001.

CARNEIRO DA CUNHA, M. Pontos de vista sobre a floresta amazônica: xamanismo e tradução. Mana, Rio de Janeiro, v. 4, n. 1, p. 7-22, 1998.

CHAUMEIL, J.-P. Varieties of Amazonian shamanism. Diogenes, Paris, n. 158, p. 101113, 1992.

CHAUMEIL, J.-P. Xamanismos de geometria variável na Amazônia. Campos, Curitiba, v. 16, n. 1, p. 148-159, 2015.

FERNANDES, E. Medicina e maneiras de tratamento entre os índios palikur. América Indígena, v. 10, n. 4, p. 309-320, 1950.

GALLOIS, D. T.; RICARDO, C. A. Povos indígenas no Brasil: vol 3: Amapá e Norte do Pará. São Paulo: CEDI, 1983. 
GOW, P. River people: shamanism and history in Western Amazonia. In: THOMAS, N.; HUMPHREY, C. (Ed.). Shamanism, history, and the state. Ann Arbor: The University of Michigan Press, 1994. p 90-114.

GOW, P. An Amazonian myth and its history. Oxford: Oxford University Press, 2001.

GOW, P. Steps towards an ethnographic theory of acculturation. Etnografia: Praktyki, Teorie, Doświadczenia, Gdańsk, v. 1, p. 34-39, 2015.

INSTITUTO BRASILEIRO DE GEOGRAFIA E ESTATÍSTICA. Estimativas da população residente no Brasil e unidades da federação. 2017. Disponível em: <ftp://ftp.ibge.gov. br/Estimativas_de_Populacao/Estimativas_2017/estimativa_dou_2017.pdf>.Acesso em: 20 maio 2017.

LANGDON, E. J. Redes xamânicas, curanderismo e processos interétnicos: uma análise comparativa. Mediações, Londrina, v. 17, n. 1, p. 61-84, 2012.

LANGDON, E. J. New perspectives of shamanism in Brazil: shamanisms and neo-shamanisms as dialogical categories. Civilisations, n. 61-2, p. 19-35, 2013.

LANGDON, E. J. A performance da diversidade: o xamanismo como modo performático. GIS, São Paulo, v. 1, n. 1, p. 9-40, 2016.

LOSONCZY, A.-M.; MESTURINI CAPPO, S. La selva viajera: rutas del chamanismo ayahuasquero entre Europa y América. Religião e Sociedade, Rio de Janeiro, v. 30, n. 2, p. 164-183, 2010.

LOSONCZY, A.-M.; MESTURINI CAPPO, S. Por que a ayahuasca? Da internacionalização de uma prática ritual ameríndia. Anuário Antropológico 2010(I), Brasília, p. 9-30, 2011.

MESTURINI CAPPO, S. Chamanisme et itinérance: réflexions sur les réseaux chamaniques qui relient l'Europe et l'Amérique du Sud. Civilisations, n. 61-2, p. 107-122, 2013.

NIMUENDAJÚ, C. Os índios palikur e seus vizinhos. Tradução de Thekla Hartmann do original “Die Palikur Indianer und ihre Nachbarn”. São Paulo. Núcleo de História Indígena e do Indigenismo/USP, 1926. Mimeografado.

PASSES, A. Not alone in the multiverse: borrowing from others, remain Pa'ikwené (Palikur). 2006. Comunicação apresentada. Colóquio Guiana Ameríndia: etnologia e história, Museu Emílio Goeldi, Belém, 2006.

PRICE, R. First time: the historical vision of an Afro-American people. Baltimore: The Johns Hopkins University Press, 1983. 
SAHLINS, M. D. Historical metaphors and mythical realities: structure in the early history of the Sandwich Islands kingdom. Ann Arbor: University of Michigan Press, 2004.

TASSINARI, A. M. I. Contribuição à história e à etnografia do Baixo Oiapoque: a composição das famílias karipuna e a estruturação das redes de troca. 1998. Tese (Doutorado em Antropologia Social)-Faculdade de Filosofia, Letras e Ciências Humanas, Universidade de São Paulo, São Paulo, 1998.

VIVEIROS DE CASTRO, E. O recado da mata. In: KOPENAWA, D.; ALBERT, B. A queda do céu: palavras de um xamã yanomami. São Paulo: Companhia das Letras, 2015. p. 11-41.

Recebido: 31/05/2017 Aceito: 14/03/2018 | Received:5/31/2017 Accepted: 3/14/2018 